\title{
Apoptosis induced by Semliki Forest virus is RNA replication dependent and mediated via Bak
}

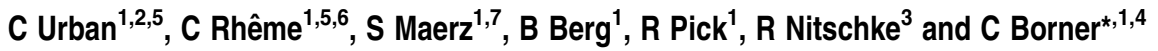

The RNA alphavirus Semliki Forest (SFV) triggers apoptosis in various mammalian cells, but it has remained controversial at what infection stage and by which signalling pathways host cells are killed. Both RNA synthesis-dependent and -independent initiation processes and mitochondrial as well as death receptor signalling pathways have been implicated. Here, we show that SFV-induced apoptosis is initiated at the level of RNA replication or thereafter. Moreover, by expressing antiapoptotic genes from recombinant SFV (replicons) and by using neutralizing reagents and gene-knockout cells, we provide clear evidence that SFV does not require CD95L-, TRAIL (tumor necrosis factor-related apoptosis-inducing ligand)- or tumor necrosis factormediated signalling but mitochondrial Bak to trigger cytochrome $c$ release, the fall in the mitochondrial membrane potential, apoptotic protease-activating factor-1/caspase-9 apoptosome formation and caspase-3/-7 activation. Of seven BH3-only proteins tested, only Bid contributed to effective SFV-induced apoptosis. However, caspase-8 activation and Bid cleavage occurred downstream of Bax/Bak, indicating that truncated Bid formation serves to amplify rather than trigger SFV-induced apoptosis. Our data show that SFV sequentially activates a mitochondrial, Bak-mediated, caspase-8-dependent and Bid-mediated death signalling pathway that can be accurately dissected with gene-knockout cells and SFV replicons carrying antiapoptotic genes. Cell Death and Differentiation (2008) 15, 1396-1407; doi:10.1038/cdd.2008.61; published online 25 April 2008

Semliki Forest virus (SFV) is an enveloped, single-stranded and positive-sense RNA virus that belongs to the genus Alphavirus of the family Togaviridae. ${ }^{1}$ Alphaviruses can be a serious health threat for humans because some strains cause fatal encephalitis or epidemic polyarthritis. For laboratory purposes, two strains, SFV and Sindbis virus (SIN), are used because they have a broad host range, replicate to high titers in many cells and are usually considered avirulent for humans. ${ }^{1}$ In mice and rats, SFV is neurotropic and hence is used as a model for viral neuropathogenesis and neurodegenerative diseases. ${ }^{2}$

Both SIN and SFV infect host cells by receptor-mediated endocytosis. Once released into the cytoplasm, the nucleocapsid dissolves and liberates its genomic RNA. ${ }^{1,2}$ The non-structural proteins nsP1-nsP4 are first synthesized as a polyprotein, which is sequentially processed by the cysteine protease activity of nsP2. NsPs generate the negative-sense
RNA, and this RNA is used for the transcription of full-length genomic plus-strand RNA and positive-sense subgenomic 26S RNA. The latter is translated into a structural polyprotein. Using its serine protease activity, the capsid cleaves itself off, and the remaining polypeptide enters the endoplasmic reticulum, where it is further processed to the envelope glycoproteins E1-E3. The glycoproteins ultimately interact with the newly formed nucleocapsid on the plasma membrane and bud off as enveloped viral particles. ${ }^{1}$

Alphaviruses are known to trigger hallmarks of apoptosis in various cultured cells ${ }^{3-5}$ as well as in vivo. ${ }^{5,6}$ This cytotoxicity has recently been exploited to kill cancer cells. ${ }^{7}$ On the other hand, cytotoxicity is a problem for the use of viral vectors for gene therapies. ${ }^{5,8}$ It is therefore necessary to understand the molecular events responsible for the demise of alphavirusinfected cells. Both death receptor and mitochondrial apoptosis signalling pathways were shown to be implicated

${ }^{1}$ Institute of Molecular Medicine and Cell Research, Center for Biochemistry and Molecular Cell Research (ZBMZ), Albert Ludwigs University Freiburg, Stefan-MeierStrasse 17, D-79104 Freiburg, Germany; ${ }^{2}$ Faculty of Biology, Albert Ludwigs University Freiburg, D-79104 Freiburg, Germany; ${ }^{3}$ Life Imaging Facility, Institute of Biology I, Albert Ludwigs University Freiburg, Hauptstrasse 1, D-79104 Freiburg, Germany and ${ }^{4}$ Spemann Graduate School of Biology and Medicine (SGBM), Albert Ludwigs University Freiburg, Albertstrasse 19a, D-79104 Freiburg, Germany

${ }^{*}$ Corresponding author: C Borner, Medical Cell Research, Institute of Molecular Medicine, Stefan-Meier-Strasse 17, D-79104 Freiburg, Germany.

Tel: + 0049761203 9618; Fax: + 0049761203 9620; E-mail: christoph.borner@ uniklinik-freiburg.de

${ }^{5}$ These authors contributed equally to this work

${ }^{6}$ Current address: GlaxoSmithKline, Talstrasse 3-5, CH-3053 Münchenbuchsee, Switzerland

${ }^{7}$ Current address: Ortenau-Klinikum Offenburg, Ebertplatz 12, D-77654 Offenburg, Germany

Keywords: apoptosis; RNA viruses; apoptosome; mitochondria; Bcl-2 family

Abbreviations: rSFV, recombinant Semliki Forest virus; SIN, Sindbis virus; TRAIL, tumor necrosis factor-related apoptosis-inducing ligand; TNF, tumor necrosis factor; nsP, non-structural protein; DISC, death-inducing signalling complex; FLIP, Fas-associating protein with death domain-like interleukin- $1 \beta$-converting enzyme inhibitory protein; MEF, mouse embryonic fibroblast; h.p.i., hours post-infection; UV, ultraviolet; SV40, simian virus 40; DKO, double knockout; PI, propidium iodide; Q-VD-OPH, QVal-Asp O-Ph, non-O-methylated; NT, N terminus; $\Delta \Psi_{\mathrm{m}}$, mitochondrial membrane potential; MTT, methyl thiazolyl tetrazolium; Apaf-1, apoptotic protease-activating factor-1; GFP, green fluorescent protein; FACS, fluorescence-activated cell sorter; XIAP, X-linked inhibitor of apoptosis protein; m.o.i.., multiplicity of infection; dsRNA, double-stranded RNA; BH3, Bcl-2 homology domain 3; PKR, double-stranded RNA-activated protein kinase; DTT, dithiothreitol; DMEM, Dulbecco's modified Eagle's medium; LAMP-1, lysosome associated membrane protein-1; PMSF, phenylmethylsulfonyl fluoride; crmA, cytokine response modifier A; wt, wild type; DEVD-AMC, acetyl-Asp(OMe)-Glu(OMe)-Val-Asp(OMe)-7-amino-4-methylcoumarin; DN, dominant negative; FCS, fetal calf serum; TMRE, tetramethylrhodamine, ethyl ester, perchlorate

Received 05.11.07; revised 06.3.08; accepted 26.3.08; Edited by M Piacentini; published online 25.4.08 
in apoptosis induced by viruses. In the death receptor pathway, stimulation of Fas/CD95, tumor necrosis factor (TNF)-R1, or tumor necrosis factor-related apoptosis-inducing ligand (TRAIL)-R1 or TRAIL-R2 leads to the formation of the death-inducing signalling complex (DISC), consisting of the adapter Fas-associated death domain and the initiator caspase-8, which directly cleaves and activates effector caspase- 3 and caspase-7. ${ }^{9}$ The mitochondrial pathway is initiated in response to diverse apoptotic stimuli that activate so-called Bcl-2 homology domain 3 (BH3)-only proteins by transcriptional or post-transcriptional means. ${ }^{10}$ These proteins trigger the mitochondrial membrane pore-forming activity of the proapoptotic Bcl-2 family members Bax and Bak by yet unknown mechanisms, ${ }^{11-13}$ leading to the release of cytochrome $c$ and other apoptogenic factors. Cytochrome $c$ recruits apoptotic protease-activating factor-1 (Apaf-1) and caspase- 9 into a high molecular mass apoptosome complex, which in turn cleaves and activates caspase- 3 and caspase7. ${ }^{14}$ This death signalling pathway can be inhibited by overexpression of the antiapoptotic Bcl-2 family members $\mathrm{Bcl}-2, \mathrm{Bcl}-\mathrm{x}_{\mathrm{L}}$ or $\mathrm{Mcl}-1 .{ }^{11}$ The death receptor and mitochondrial pathways can cross talk through the BH3-only protein Bid, which, under conditions of low DISC formation, is cleaved by caspase- 8 to a truncated form (tBid) that is targeted to mitochondria to activate Bak and Bax. ${ }^{15}$ For DNA viruses, virally encoded survival factors of the Bcl-2 family or proteins interfering with death receptor signalling have helped to dissect the death signalling pathways in host cells. ${ }^{16,17} \mathrm{By}$ contrast, RNA viruses usually do not encode survival factors in their genome, and hence uncovering the relevant death signalling components has been more difficult. ${ }^{18-24}$ Here, we show that SFV requires an intact RNA genome and a Bak/ mitochondria-mediated signalling pathway for apoptosis induction.

\section{Results}

SFV requires an intact RNA genome for caspasedependent and caspase-independent apoptosis. It has been controversial whether SFV or SIN kills host cells via receptor binding/endocytosis or RNA replication. ${ }^{25-27}$ By infecting 3T9 mouse embryonic fibroblasts (MEFs) with ultraviolet (UV)-inactivated SFV and monitoring virus uptake, RNA replication and apoptosis induction, we clearly show that SFV requires an intact RNA genome to induce classical features of apoptosis (Supplementary Material and Supplementary Figure 1). Effective apoptosis is mediated via the activation of caspases. As shown in Figure 1a and b, SFV induced caspase-3/-7 activity and pro-caspase-3 cleavage to the active p17 fragment at $0-36 \mathrm{~h}$ post-infection (h.p.i.). To test if caspase-3 and/or caspase-7 were required for
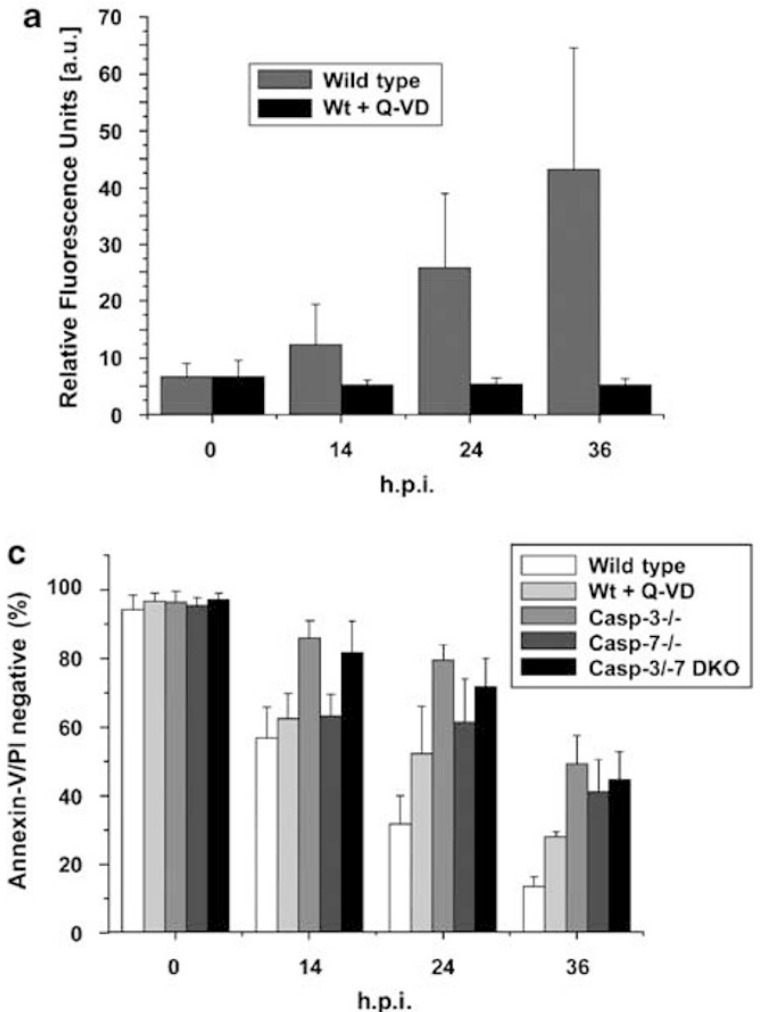

b

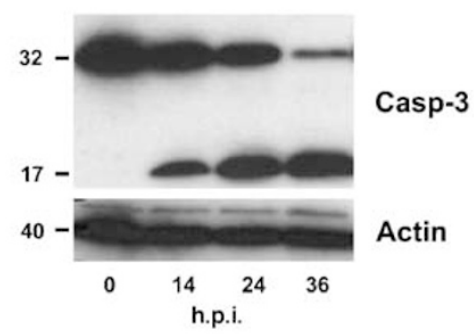

d

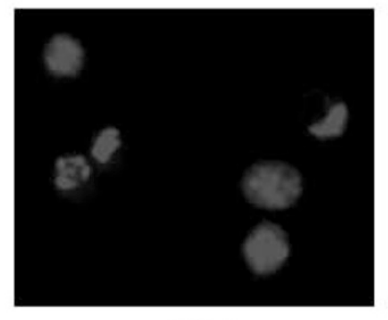

- Q-VD

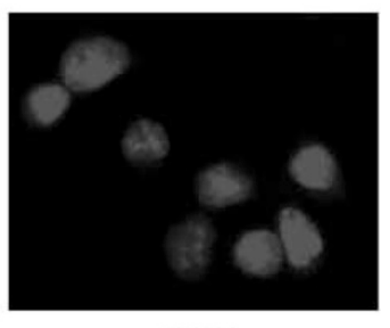

$+Q-V D$

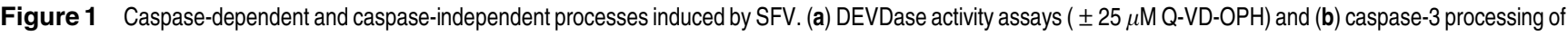
the cytosols of SV40-transformed MEFs infected with SFV (10 m.o.i.) for 0, 14, 24 and $36 \mathrm{~h}$. (c) FACS analysis of His-GFP-annexin-V/PI-stained SV40-transformed, wt ( $\pm 25 \mu \mathrm{M}$ Q-VD-OPH), caspase-3-/-, caspase-7-I- and caspase-3/-7-I- MEFs infected with SFV for 0-36 h. Percentage of annexin-V/PI-negative (lower left quadrant of FACS = 'surviving') cells is depicted. (d) Nuclear morphology of SFV-infected cells (24 h.p.i.) in the absence or presence of $25 \mu \mathrm{M}$ Q-VD-OPH, assessed by Hoechst 33342 staining. (a, c) The data represent the means of at least five independent experiments \pm S.E.M. (b) Probing for actin is shown as loading control 
SFV-induced apoptosis, we infected simian virus 40 (SV40)transformed caspase-3-/-, caspase-7-/- or caspase-3/-7 double-knockout (DKO) MEFs with SFV for 0-36 h and analyzed the cells for PS exposure and membrane permeability. Figure 1c shows that all three knockout cell lines were similarly protected from green fluorescent protein (GFP)-annexin-V/propidium iodide (PI) staining. However, PS exposure and increased membrane permeability were evident with time indicating the coexistence of a caspaseindependent death signalling pathway. To bolster our findings, we treated SV40 MEFs with $25 \mu \mathrm{M}$ of the broadrange caspase inhibitor Q-Val-Asp O-Ph, non-O-methylated (Q-VD-OPH) during SFV infection. GFP-annexin-V/PI staining of these cells revealed a marked delay but not blockage of SFV-induced apoptosis in the presence of Q-VD$\mathrm{OPH}$ (Figure 1c). Moreover, nuclear fragmentation, a caspase-3/-7-mediated response, was greatly diminished in Q-VD-OPH-treated cells (Figure 1d). Thus, caspase-3 and caspase-7 are dominant and redundant mediators of SFVinduced apoptosis, but the virus also triggers a caspaseindependent death program.

\section{SFV uses the mitochondrial/apoptosomal pathway for apoptosis induction. To delineate the signalling} components of SFV-induced apoptosis, we first investigated the mitochondrial pathway. For that purpose, we investigated cytochrome $c$ release of SFV-infected MEFs by immunofluorescence and immunoblot analyses and compared this release to the proteolytic processing and activation of caspase-3. As shown in Figure $2 a$, after 10 h.p.i., cytochrome $c$ changed its localization from elongated mitochondrial structures to the cytosol. Each cell showing diffusely stained cytochrome $c$ also stained positive for active caspase-3, indicating that cytochrome $c$ release occurred before or concomitant with caspase-3 activation. Western blot analysis confirmed that cytochrome $c$ appeared in cytosolic fractions at $>10$ h.p.i. and that this correlated with caspase-3 processing to the active $17-\mathrm{kDa}$ fragment (Figure 2b). Next, we studied the formation of the Apaf-1/ caspase-9 apoptosome, a known downstream effector of cytochrome $c$. Using Superose 6 gel filtration chromatography of mock- and SFV-infected MEF cytosols, we observed the formation of high molecular mass Apaf-1/ caspase- 9 complexes $(700 \mathrm{kDa})$ by 14 h.p.i. (Figure $2 \mathrm{c})$. Moreover, caspase- 9 appeared to be activated, as it was processed from its p46 proform to the active p37/p35 forms at 14-24 h.p.i. (Figure 2d). In agreement with these findings,
3T9 MEFs deficient of caspase-9 and Apaf-1 showed markedly decreased apoptosis after 24-36h.p.i. as quantified by GFP-annexin-V/PI staining (Figure 2e). However, apoptosis was not entirely blocked, as up to $40 \%$ $(24 \mathrm{~h})$ and $55 \%(36 \mathrm{~h})$ of the SFV-infected $\mathrm{KO}$ cells continued to die (Figure $2 \mathrm{e}$ ).

SFV predominantly uses Bak and not Bax for cytochrome $c$ release and effective apoptosis induction. Mitochondrial membrane perforation depends on the action of Bax and Bak, as in their absence cytochrome $c$ release and apoptosis are blocked. ${ }^{28}$ To determine if Bax and Bak contributed equally to cell killing in response to SFV, we measured cytochrome $c$ release, the fall in the mitochondrial membrane potential $\left(\Delta \Psi_{\mathrm{m}}\right)$, caspase3 activation, and the extent of cell death (methyl thiazolyl tetrazolium (MTT) assay) and apoptosis (GFP-annexin-V/PI staining) in Bax-/-, Bak-/- and Bax/Bak DKO 3T9 cells at 0-36h.p.i. For this analysis, cytochrome $c$ release was measured by a quantitative fluorescence-activated cell sorter (FACS) analysis on digitonin-permeabilized fixed cells. Strikingly, Bax-1- 3T9 MEFs were more susceptible to SFV-induced cell death/apoptosis than wild-type (wt) cells (Figure $3 a$ and $b$ ) and hence displayed a greater cytochrome $c$ release (Figure $3 \mathrm{c}$ ), $\Delta \Psi_{\mathrm{m}}$ diminution (Figure $3 \mathrm{~d}$ ) and caspase-3 processing/activation (Figure $3 e$ and $\mathrm{f}$ ) at all times after SFV infection. By contrast, as expected, Bax/Bak DKO 3T9s were protected from cell death induced by SFV (Figure $3 a$ and b). At 24 h.p.i., $\Delta \Psi_{m}$ was still maintained, and cytochrome $c$ release and caspase-3 activation were hardly detected (Figure 3c-f). However, as with caspase-3-/-, caspase-9-/- and Apaf-1-/- cells, cell death continued at later time points (Figure $3 a$ and $b$ ), indicating the coexistence of a Bax/Bak-independent death signalling pathway. The marked difference in apoptosis susceptibility of Bax-1- and Bax/Bak DKO cells suggested a crucial role of Bak in SFVinduced apoptosis. Indeed, Bak-/- 3T9 cells were almost as resistant to SFV-induced cell death and apoptosis as Bax/ Bak DKO (Figure $3 a$ and $b$ ). In addition, Bak-/- cells exhibited a markedly delayed cytochrome $c$ release (Figure 3c), fall in $\Delta \Psi_{\mathrm{m}}$ (Figure $3 \mathrm{~d}$ ) and caspase-3 processing (Figure $3 e$ and f). Consistently, we detected a significant Bak activation by FACS analysis of its $\mathrm{N}$-terminal conformational change in wt (21-39\%) and Bax-/- (26\%) 3T9s at 14-24h.p.i. (Figure 3g). Such a conformational change was seen only slightly for Bax, even in Bak-/- cells (9\%) (Figure $3 \mathrm{~g}$ ). Importantly, cell death protection of

Figure 2 Cytochrome $c$ release, apoptosome formation and caspase-9 activation and the requirement of the apoptosome for SFV-induced apoptosis. (a) Anti-cytochrome $c$ (green) and anti-active caspase-3 (red) immunofluorescence analysis of 3 T9 wt MEFs infected with $10 \mathrm{~m} .0 . \mathrm{i}$. SFV for $0,10,12$ and $14 \mathrm{~h}$, showing concomitant release of cytochrome $c$ (diffuse cytoplasmic staining) with caspase-3 activation in response to viral infection (white arrows). Magnification is $\times 630$. (b) Western blot analysis of cytochrome $c$ (cytosol) and caspase-3 (total extracts) from 3 T9 cells infected with SFV for $0,6,8,10,14$ and $24 \mathrm{~h}$. Note that at every time point the appearance of cytochrome $c$ in the cytosol correlates with caspase-3 processing from the inactive $32 \mathrm{kDa}$ to the active $17 \mathrm{kDa}$ form. (c) Anti-Apaf-1 western blot analysis of gel filtration fractions from the cytosols of mock-infected and SFV-infected 3 T9 cells (14 h.p.i.) showing the formation of the ca. $700 \mathrm{kDa}$ apoptosome in infected cells. Standard proteins with defined molecular masses are indicated and described in Materials and Methods. (d) Anti-caspase-9 western blot analysis of cytosols of 3 T9 cells infected with SFV for 0,14 and $24 \mathrm{~h}$ showing the formation of the active p37/p35 caspase-9 fragments from the inactive p46 proform upon SFV infection. (e) FACS analysis of His-GFP-annexin-V/PI-stained wt, caspase-9-I- and Apaf-1-/- ( $\pm 25 \mu \mathrm{M}$ Q-VD-OPH) 3 T9 cells infected with SFV for 0, 14, 24 and $36 \mathrm{~h}$. Percentage of annexin-V/PI-negative cells is depicted. (e) The data represent the means of at least three independent experiments \pm S.E.M. (b, d) Probings for actin (cytosol) and the F1 subunit of mitochondrial ATP synthase (ATP-S) are shown as loading controls 
Bak-/- and Bax/Bak DKO cells was not due to a blockage of virus production, as cells of all genotypes produced similar amounts of viruses (Table 1).
Redundancy of BH3-only proteins to activate Bak and apoptosis after SFV infection: partial role of Bid. To identify which $\mathrm{BH} 3-$ only protein was responsible for sensing a

Cyt $c$
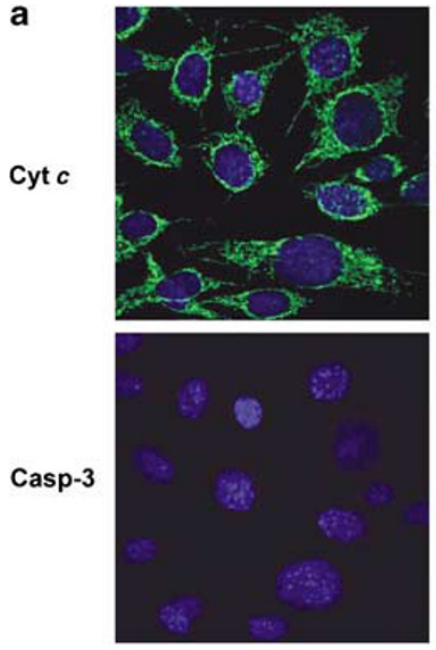

0
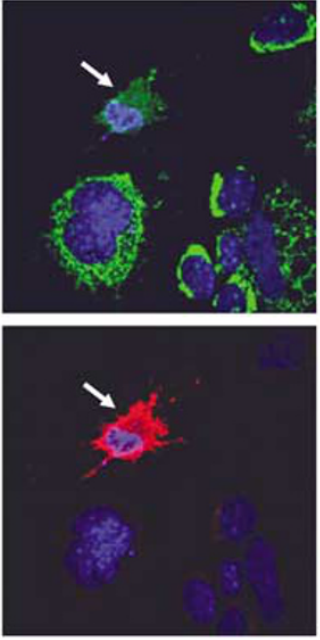

10
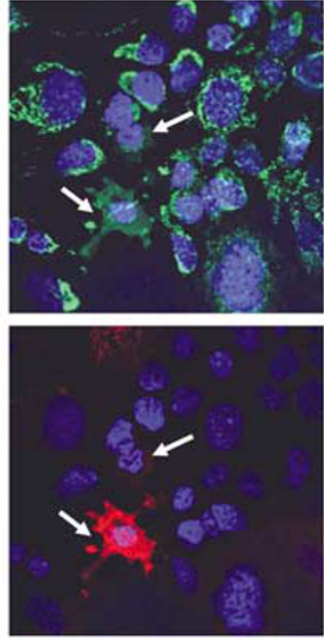

12
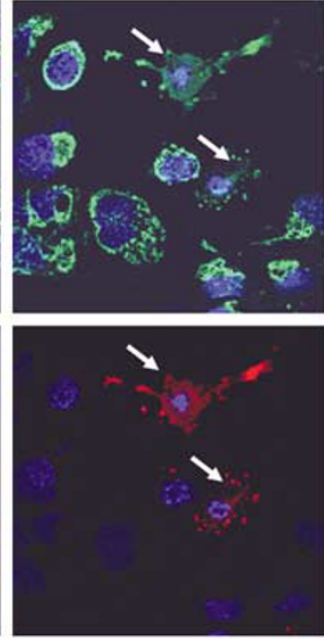

14 h.p.i b

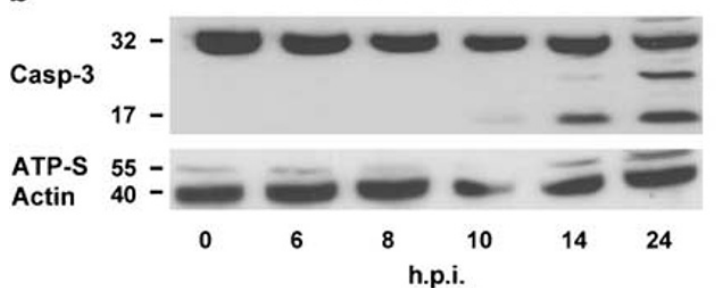

Cytosol

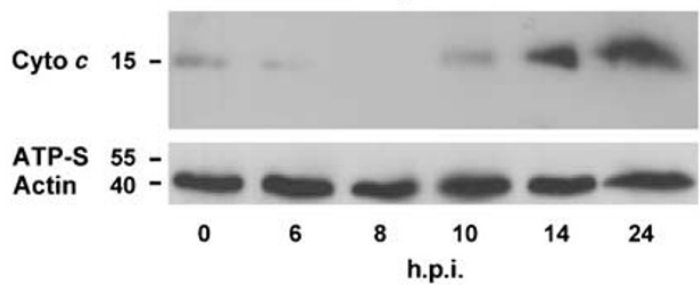

$68 \mathrm{kDa}$

c

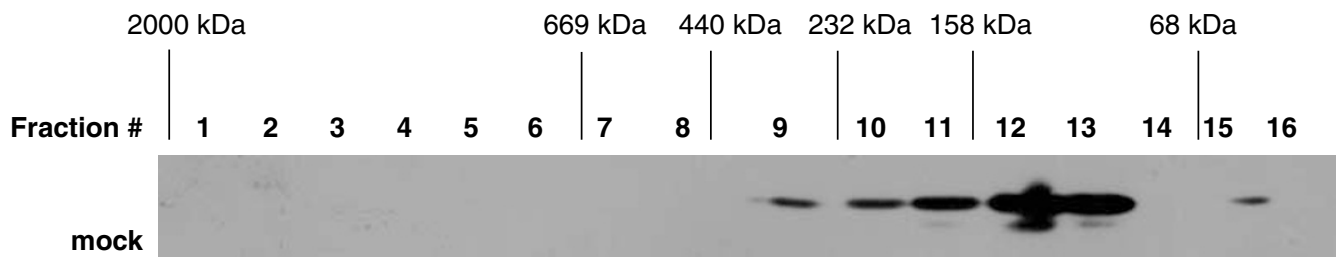

SFV 14 h.p.i.

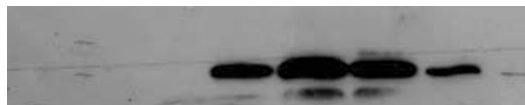

ca. $700 \mathrm{kDa}$

Apoptosome

Free Apaf-1

d

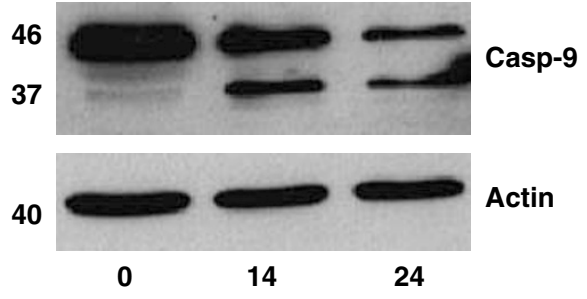

e

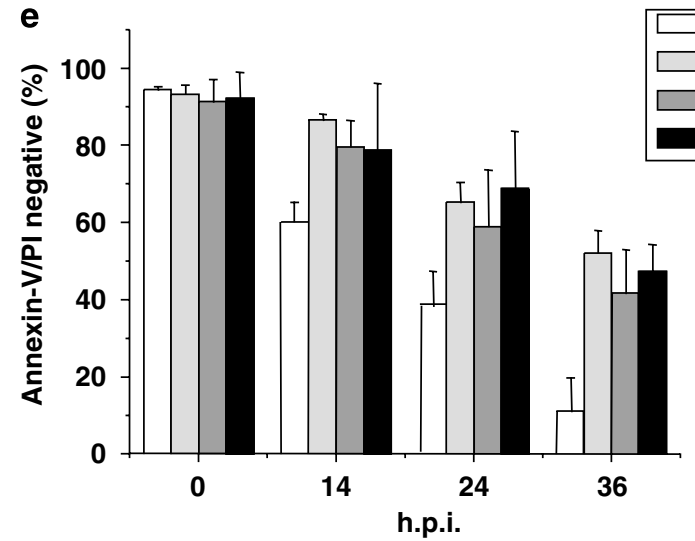

Wild type

Casp-9-/-

Apaf-1-/-

Apaf-1-/- + Q-VD 

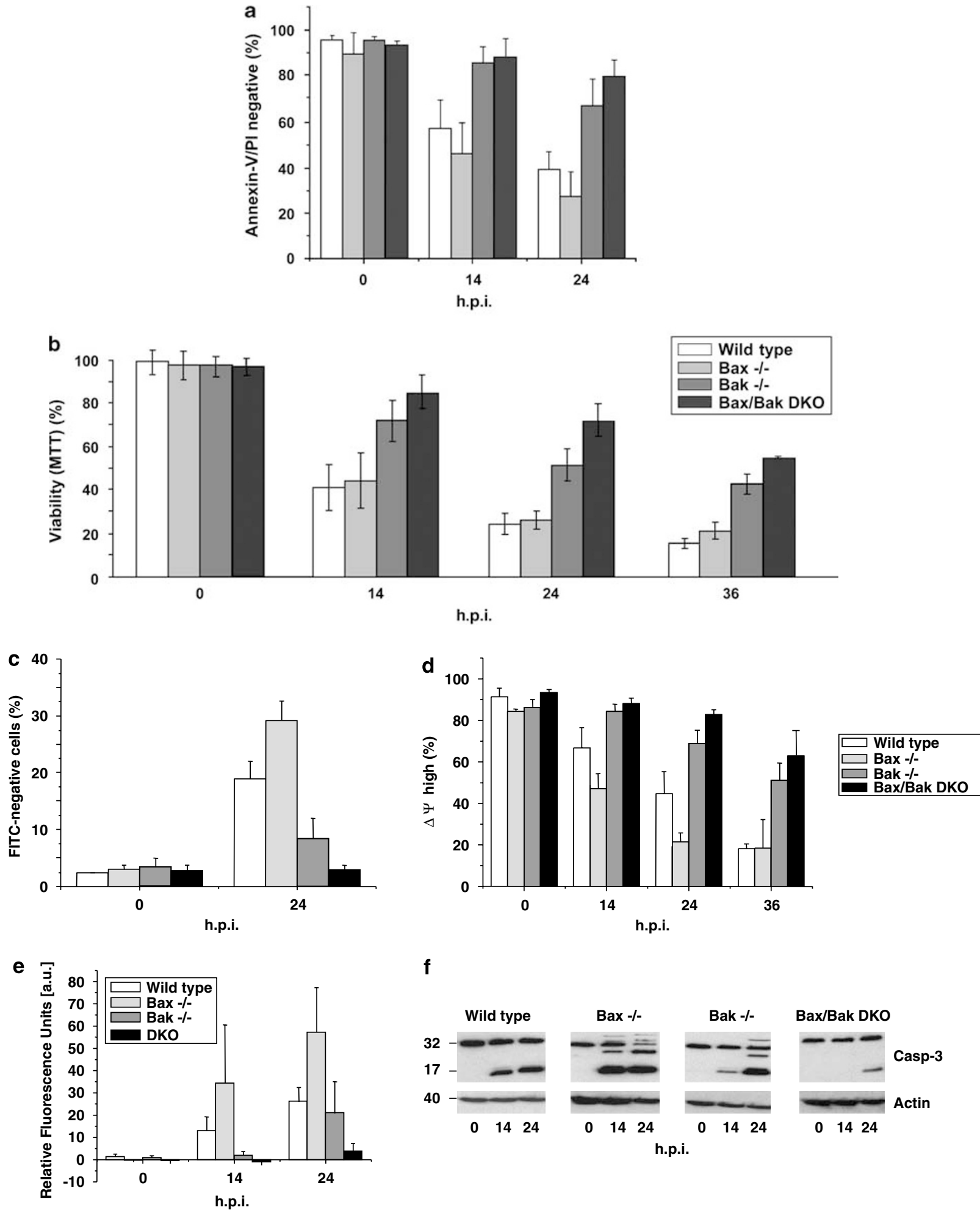

$\mathbf{f}$

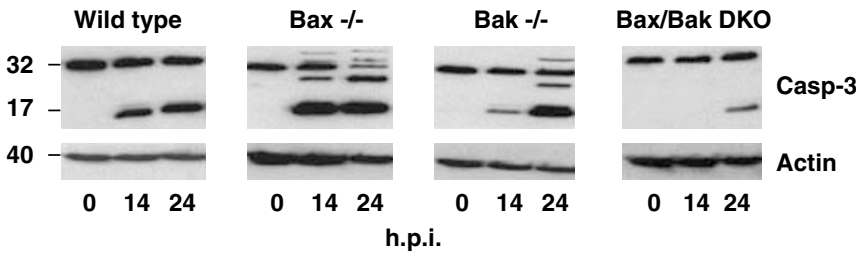

Figure 3 Predominant role of Bak in SFV-induced apoptosis. (a) FACS analysis of His-GFP-annexin-V/PI staining, (b) MTT viability assay, (c) FACS analysis of cytochrome $c$ release, (d) FACS analysis of TMRE (tetramethylrhodamine, ethyl ester, perchlorate) staining (measuring the mitochondrial membrane potential, $\Delta \Psi_{\mathrm{m}}$ ) (e) DEVDase activity assays of cytosolic caspase-3 and (f) western blotting analysis of cytosolic caspase-3 of wt, Bax-/-, Bak-/- and Bax/Bak DKO 3 T9 cells infected with SFV for 0-36 h. (g) N-terminal conformational changes of Bax and Bak quantified by anti-NT-Bax or anti-NT-Bak FACS analysis of fixed wt, Bax-1- and Bak-1-3T9 MEFs infected with SFV for 0,14 and $24 \mathrm{~h}$. The percentage indicates the number of cells, which show staining with the NT antibodies (shift from the blue to the red curve). (a-e) The data represent the means of at least three independent experiments \pm S.E.M. (c) Mitochondrially retained cytochrome $c$ was measured (see Materials and Methods) and the loss of cytochrome $c$ from mitochondria calculated as a percentage difference. (f) Probing for actin is shown as loading control 
g
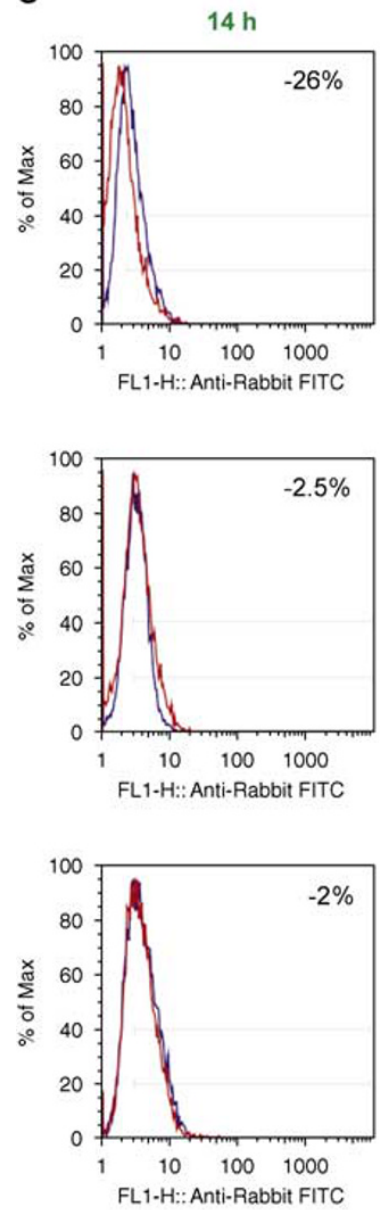

Anti-Bax NT FACS
Wild type
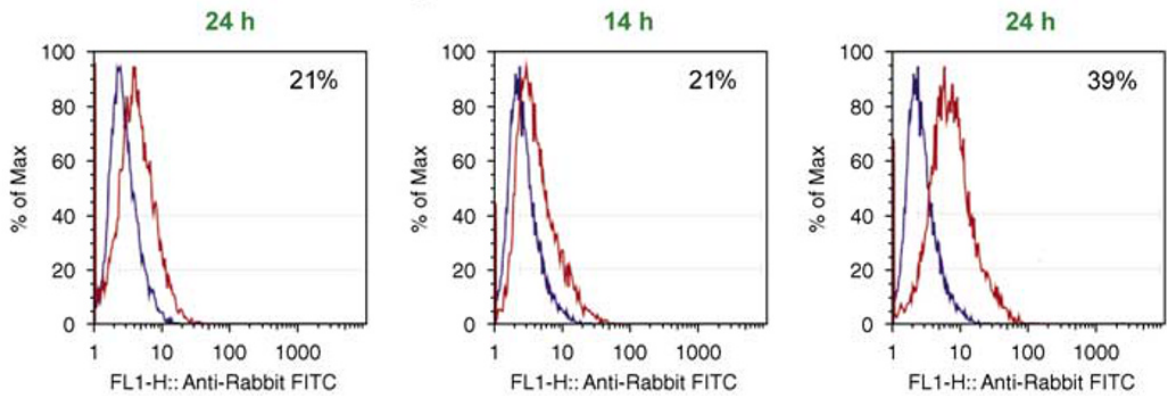

Bax-/-
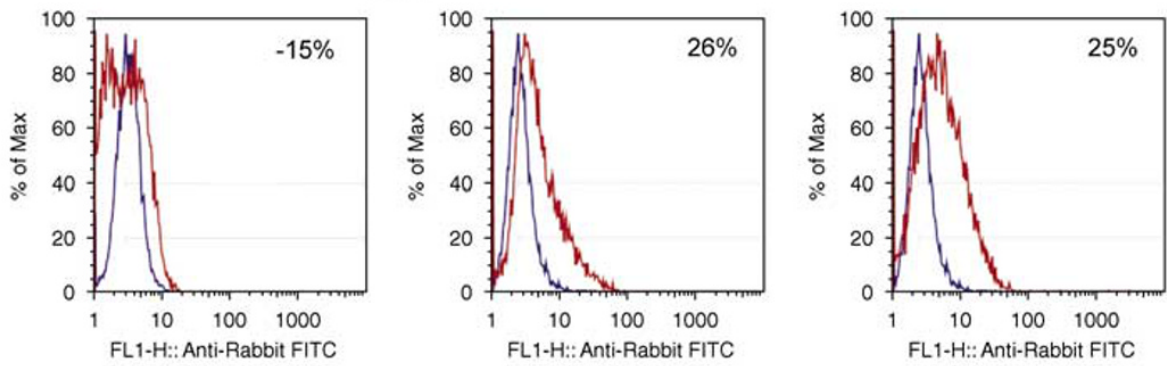

Bak-/-
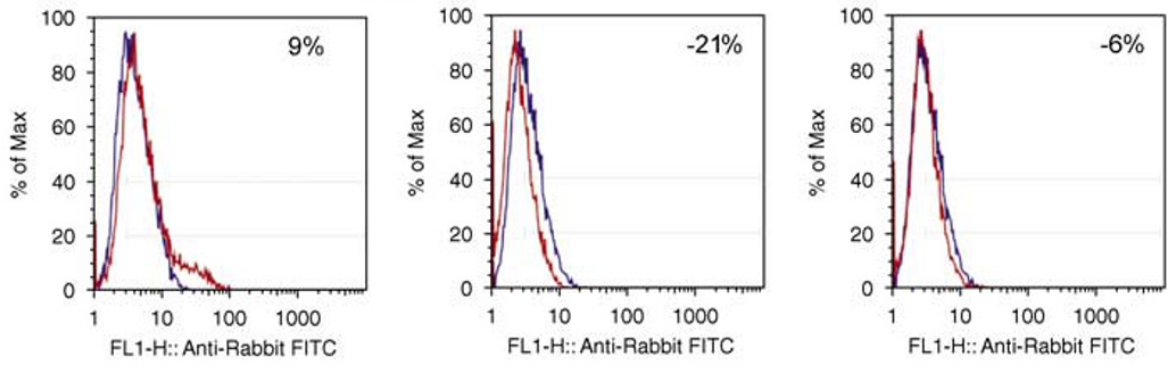

Anti-Bak NT FACS

Figure 3 Continued

SFV infection and transferring the death signal to Bak activation on mitochondria, we measured the kinetics of SFV-induced annexin-V/PI staining in 3T9 MEFs lacking expression of one or two BH3-only protein(s). As shown in Figure 4a, MEFs deficient in Bim, Bik, Bmf, Bad, Puma, Noxa or a combination of Bim and Bad (Bim/Bad DKO) died in response to SFV infection in a similar way as wt MEFs. By contrast, SV40-transformed Bid-/- and Bid/Bim DKO MEFs were slightly protected (Figure $4 \mathrm{~b}$ ). Although this protection was only $20-25 \%$, it was significant, occurred in two independent cell lines isolated from two different mouse genotypes (Bid-/- and Bid/Bim DKO) and was also detected in the MTT viability assay (Figure 4c). These data demonstrate that SFV does not depend on the single BH3-only proteins Bim, Bmf, Noxa, Puma, Bad or Bik for apoptosis induction but relies partially on Bid.

Caspase-8 and tBid are downstream amplifiers of mitochondrial signaling. SIN-induced apoptosis was shown to be inhibited by the caspase-8 inhibitors FLIP (Fas-associating protein with death domain-like interleukin-1 $\beta$-converting enzyme inhibitory protein) ${ }^{23}$ and crmA (cytokine response modifier $A) .{ }^{24}$ This suggested the involvement of the extrinsic death receptor pathway in alphavirus-induced apoptosis and would explain the partial dependence on the major caspase-8 substrate Bid. By using neutralizing antibodies or $F_{c}$ constructs to Fas, TRAIL-R2 and TNF-R1 as well as to their ligands, we found that SFV did not require death receptors or ligands for apoptosis signalling (Supplementary Material and Supplementary Figure 2). Western blot analysis of caspase-8 and Bid, however, revealed that both proteins were cleaved to their active forms in response to SFV infection. Strikingly, both cleavages were significantly delayed and even blocked in Bak-I- and Bax/Bak DKO cells, respectively (Figure 5). On the other hand, as seen for cytochrome $c$ release, $\Delta \Psi_{\mathrm{m}}$ diminution, caspase-3 activation and extent of cell death (Figure 3), the processing of caspase-8 and Bid was even faster in Bax-1- than wt cells (Figure 5). These data strongly indicate that caspase- 8 activation and tBid formation were Bak dependent and thus occurred downstream of mitochondria.

Replicon-based SFV carrying antiapoptotic genes confirms the role of the mitochondrial pathway in SFV-induced apoptosis. To confirm the implication of the 

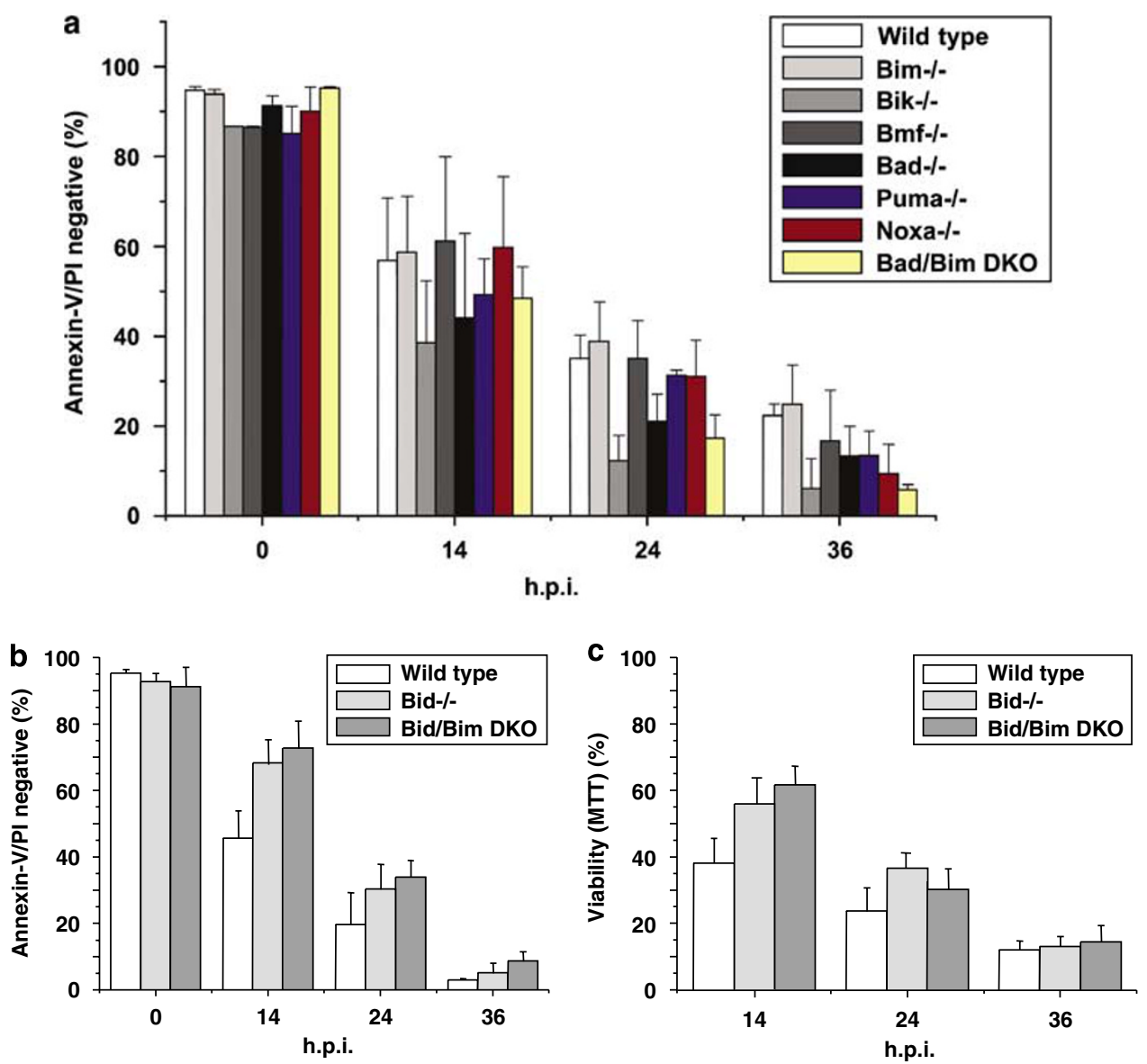

Figure 4 Role of BH3-only proteins in SFV-induced apoptosis: partial implication of Bid. FACS analysis of His-GFP-annexin-V/PI staining of SFV-infected (a) wt, Bim-/-, Bik-/-, Bmf-/-, Bad-/-, Puma-/-, Noxa-/- and Bad/Bim DKO 3T9 MEFs and (b) SV40-transformed wt, Bid-/- and Bid/Bim DKO MEFs at 0-36 h.p.i. Panels a and $b$ are shown separately because two different controls (3T9 and SV40 wt MEFs) were used. (c) MTT viability assay of SV40-transformed wt, Bid - / - and Bid/Bim DKO MEFs infected with SFV for 14, 24 and $36 \mathrm{~h}$. Mock-treated cells represent $100 \%$ of MTT staining. The data represent the means of three (a) and five (b, c) independent experiments \pm S.E.M.

a

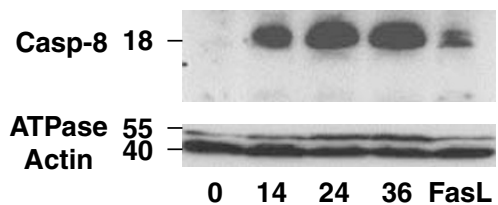

Bax -/-

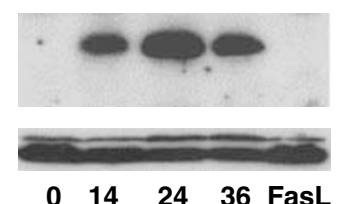

Bak -/-

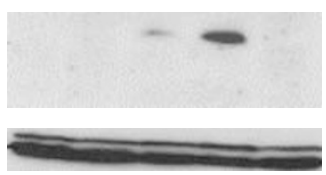

$\begin{array}{lllll}0 & 14 & 24 & 36 & \text { FasL }\end{array}$
Bax/Bak DKO

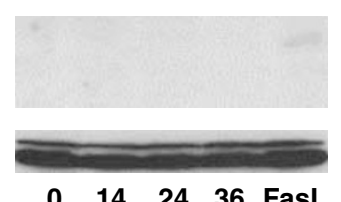

b
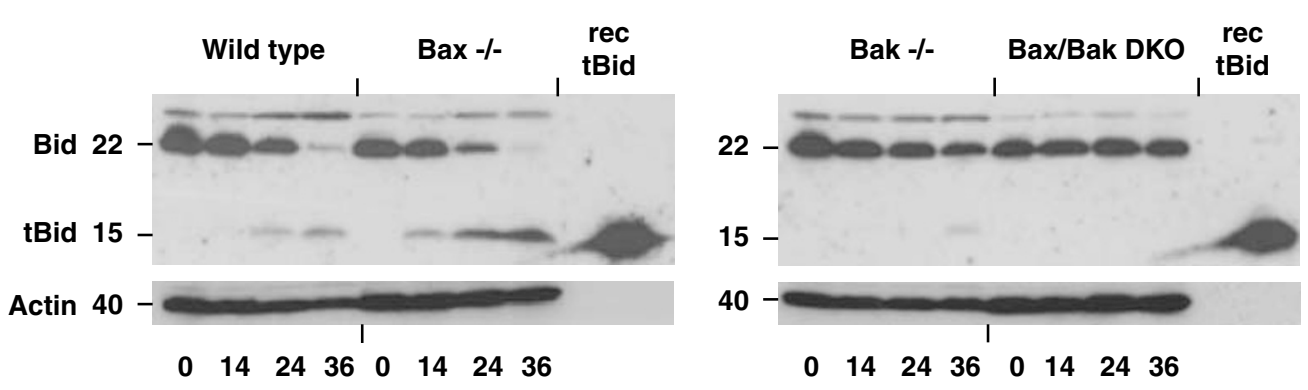

Figure 5 SFV-induced processing of caspase-8 and Bid dependent on Bak, that is, downstream of mitochondria. Anti-mouse caspase-8 (a) and anti-mouse Bid (b) western blots of total extracts of wt, Bak-/-, Bax-/- and Bax/Bak DKO 3T9 cells infected with 10 m.o.i. SFV for $0,14,24$ and $36 \mathrm{~h}$. Blots show the formation of the active p18 fragment of caspase-8 and the truncated p15 fragment Bid (tBid) from p22 full-length Bid in response to SFV infection. A control treatment with $50 \mathrm{ng} / \mathrm{ml}$ CD95/FasL for $2 \mathrm{~h}$ is shown in (a) and recombinant tBid $(50 \mathrm{ng})$ is co-analyzed in (b). The band of the p55 caspase-8 precursor full-length form was cut off, because due to high abundance, its intense chemiluminescence signals would have interfered with the detection of the cleaved form. Probings for actin and ATP synthase are shown as loading controls 


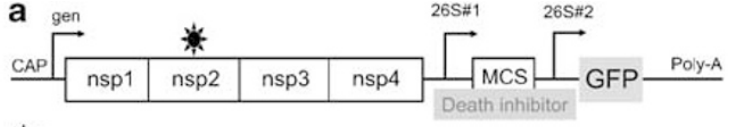

Encapsidation signal
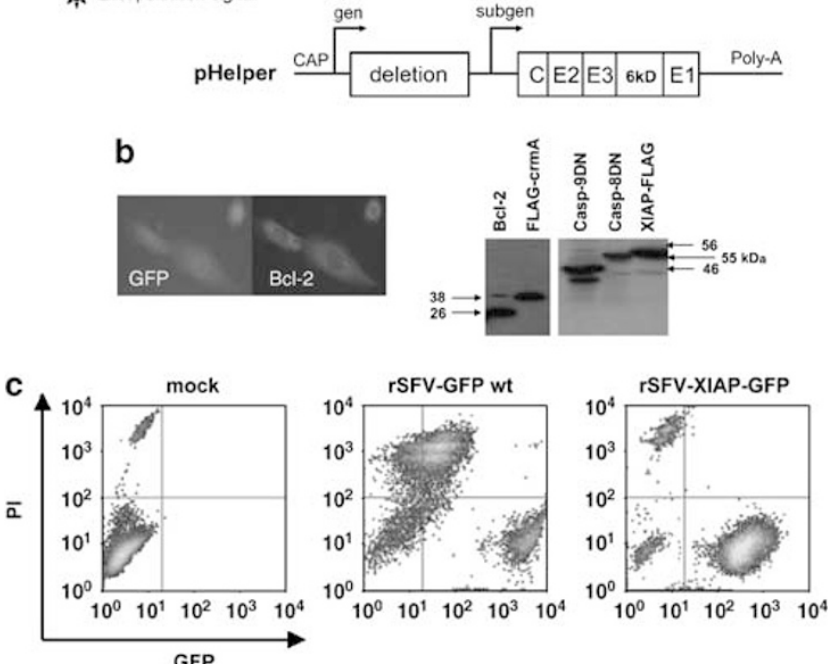

d

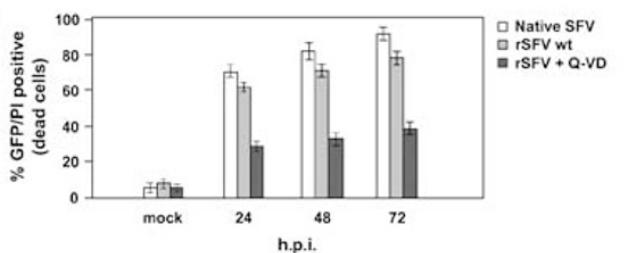

e

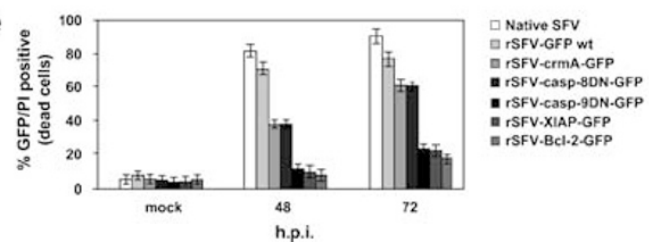

Figure 6 Confirmation of the implication of the mitochondrial/apoptosomedependent pathway in SFV-induced apoptosis by using rSFV-expressing apoptosis inhibitory proteins. (a) Strategy of producing rSFV. The two identical subgenomic 26 S promoters drive GFP expression on one hand (26S\#2) and the expression of a death inhibitor cloned into the multiple cloning site (MCS) on the other hand (26S\#1). Transfection of in vitro synthesized mRNA of these constructs along with helper mRNA carrying the structural proteins and the encapsidation signal into BHK-21 cells leads to the production of recombinant, GFP-positive SFV. (b) Coexpression of GFP and mouse Bcl-2 in 3T9 MEFs infected with rSFV-Bcl2-GFP, detected by anti-Bcl-2 immunofluorescence. Anti-Bcl-2 (26 kDa), anti-FLAG (crmA, $38 \mathrm{kDa}$; XIAP, $56 \mathrm{kDa}$ ), anti-caspase-9 (46 kDa) and anti-caspase-8 (55 kDa) western blot analysis showing the overexpressed proteins in total extracts of $3 \mathrm{~T} 9$ MEFs infected with rSFVs carrying the respective death inhibitor construct. On the left blot, anti-FLAG and anti-Bcl-2 were coincubated, and on the right blot, anticaspase-8, caspase-9 and anti-FLAG. (c) FACS analysis of GFP-positive (successfully infected) and PI-positive (dying) 3T9 MEFs infected with wt or XIAP expressing, recombinant rSFV-GFP for $24 \mathrm{~h}$. The MEFs infected with rSFV-GFP wt lose GFP and gain PI staining (cell death), whereas those infected with rSFV-XIAPGFP retain GFP fluorescence and do not show any PI staining. (d) Death quantitation (\% GFP/PI double positive) of 3T9 MEFs infected with native SFV or recombinant rSFV-GFP wt for 24,48 and 72 h.p.i. in the absence and presence of Q-VD-OPH. (e) Quantitation of cell death as shown in (d) but with recombinant rSFV-GFP carrying crmA, casp-8 DN, casp-9 DN, XIAP or Bcl-2. As comparison, infections with native SFV and rSFV-GFP wt were run in parallel. (d, e) The data represent the means of at least three independent experiments \pm S.E.M.
Table 1 SFV plaque assay

\section{Cell type}

Virus titer in PFU/ml (24 h.p.i.)

3T9 wt

3T9 wt (10 m.o.i., UV-treated)

3T9 wt (200 m.o.i., UV-treated)

3T9 Bax-1-

3T9 Bak-/-

3T9 Bax/Bak DKO

3T9 caspase-9-1-

3T9 Apaf-1-/-

3T9 Apaf-1-/-+Q-VD-OPH

SV40 wt

SV40 wt+Q-VD-OPH

SV40 caspase-3-1-

SV40 caspase-7-1-

SV40 caspase-3/-7 DKO

SV40 Bid-/-

SV40 Bid/Bim DKO
$1.3 \pm 0.3 \times 10^{9}$ $<10^{2}$

$2.5 \pm 0.3 \times 10^{6}$

$2.0 \pm 0.5 \times 10^{9}$

$1.6 \pm 0.2 \times 10^{9}$

$2.0 \pm 0.4 \times 10^{9}$

$6.0 \pm 0.5 \times 10^{9}$

$3.5 \pm 0.3 \times 10^{9}$

$3.3 \pm 0.4 \times 10^{9}$

$3.7 \pm 0.4 \times 10^{8}$

$7.0 \pm 0.5 \times 10^{8}$

$5.0 \pm 0.4 \times 10^{7}$

$1.4 \pm 0.2 \times 10^{8}$

$1.2 \pm 0.1 \times 10^{9}$

$1.9 \pm 0.2 \times 10^{9}$
$1.3 \pm 0.2 \times 10^{8}$

mitochondrial signalling pathway in SFV-induced apoptosis, we generated replicon-based recombinant SFV (rSFV) where the structural genes were replaced by the reporter gene GFP (pSFV2subGFP wt) and an antiapoptotic gene of interest under two $26 \mathrm{~S}$ subgenomic promoters in tandem (26S\#1 and 26S\#2) (Figure 6a). The rationale of this approach was that after transduction of such viruses, the expression of the antiapoptotic transgene would interfere with a particular apoptosis signalling pathway, provided that its expression was sufficiently high and faster than apoptosis execution by the virus. Moreover, by the simultaneous expression of GFP and the antiapoptotic gene, it was possible to determine transfection efficiency and transgene expression and to monitor the apoptotic fate (PI staining) of the GFP-positive cells by FACS analysis without selecting cell clones. We generated recombinant viruses carrying $\mathrm{Bcl}-2$, the caspase-3/-9 inhibitor X-linked inhibitor of apoptosis protein (XIAP), the caspase-8 inhibitor crmA or dominant-negative (DN) forms of caspase-8 or caspase-9. Infection of 3T9 MEFs with these viruses resulted in the coexpression of GFP and the respective antiapoptotic transgene (Figure 6b). To quantify cell death by rSFV, we performed an FACS analysis where the expression of the transgenes was measured by GFP fluorescence and cell death by PI staining (secondary necrotic cells, see above). As shown in Figure 6c, mock-infected 3T9 cells displayed no GFP (no transgene expression) and only little PI staining. By contrast, cells infected with the recombinant wt rSFV-GFP showed a double-positive GFP/PI staining after $24 \mathrm{~h}$ indicative of cell death of GFP-positive cells (Figure 6c). The cell death kinetics between infections with the native SFV and recombinant wt SFV were strikingly similar over a range of $0-72$ h.p.i. (Figure $6 \mathrm{~d}$ ). Moreover, as for the native SFV, cell death induced by rSFV was both caspasedependent and caspase-independent, as the addition of QVD-OPH blocked only approximately $50 \%$ of GFP/PI positivity (Figure 6d). This indicates that the structural genes, which are missing in rSFV, are not needed for cell death induced by SFV. As expected from our data above, 3T9 MEFs infected with rSFV carrying Bcl-2, XIAP or caspase-9 DN showed only a few PI-positive cells and 
maintained GFP expression for up to $72 \mathrm{~h}$ (Figure $6 \mathrm{c}$ and e). By contrast, cells infected with SFV containing crmA or caspase-8 DN were more readily killed but not as much as with recombinant wt rSFV-GFP (Figure 6e). These data show that rSFV expressing antiapoptotic genes can be used to dissect apoptosis signalling pathways and confirm that the major pathway used by SFV passes through mitochondria and the apoptosome with a possible downstream amplification via caspase-8.

\section{Discussion}

We present three novel findings on the mechanisms of SFVinduced apoptosis. Firstly, apoptosis of the host is initiated at the level of viral RNA replication or thereafter. Secondly, apoptotic signalling involves the mitochondrial pathway with a preferential activation of Bak over Bax. Thirdly, effective apoptosis seems to depend, at least in part, on an amplification loop implying a caspase-8-mediated cleavage of Bid downstream of mitochondria. In addition, we show for the first time that recombinant alphaviruses (replicons) expressing various death inhibitors can be used to dissect virus-induced death signalling pathways.

The successful blockage of apoptosis signalling by replicons encoding antiapoptotic proteins confirms that SFV does not initiate apoptosis before RNA replication/transcription. Moreover, as shown by plaque assays (Table 1), virus formation was independent of apoptosis sensitivity. Our findings, however, contradict a previous report stating that SIN-induced apoptosis was initiated at the level of viral entry. ${ }^{25} \mathrm{~A}$ possible explanation for this discrepancy may be the 20- to 50-fold higher infection dose (200-500 multiplicity of infection (m.o.i.)) used in their UV-inactivation experiment. We found that if MEFs were infected with 200 instead of 10 m.o.i. of UV-inactivated SFV, the cells were still killed and produced lower titers of viruses, indicating that with higher m.o.i. the RNA genome may have been incompletely inactivated by UV (Supplementary Figure 1F and Table 1).

Another controversy has been the nature of the apoptosis signalling pathway activated by alphaviruses. For both SFV and SIN, it was shown that overexpression of $\mathrm{Bcl}-2, \mathrm{Bcl}-\mathrm{X}_{\mathrm{L}}$ or their binding partner Beclin-1 blocked apoptosis. ${ }^{3,4,6,19,20}$ Moreover, Moriishi et al. ${ }^{21}$ reported the implication of the $\mathrm{BH} 3-$ only protein Bad in SIN-induced apoptosis. Although these data suggested the importance of the mitochondrial pathway in alphavirus-induced apoptosis, no proof was presented using discrete knockout or knockdown expression systems. Here, we show that SFV-induced apoptosis is strongly delayed in Bak-/-, Bax/Bak DKO, caspase-9, Apaf-1, and caspase- 3 and caspase-3/-7 DKO cells. However, we could not confirm that Bad is per se an important upstream sensor/activator of the mitochondrial pathway. Bad-/-, Bad/ Bim DKO and most other single BH3-only knockout MEFs were as sensitive to SFV-induced apoptosis as wt counterparts. Thus, SFV-induced apoptosis either does not require any $\mathrm{BH} 3-o n l y$ protein or is sensed by a specific combination of these proteins.

Previous reports suggested the implication of death receptor signalling in SFV- or SIN-induced apoptosis, as the caspase-8 inhibitors VFLIP and crmA could delay or prevent the death process. ${ }^{23,24}$ However, as the caspase-8/tBid pathway can also be activated downstream of mitochondria, presumably via caspase-6- and/or caspase-3-mediated processing of caspase-8 and/or Bid, ${ }^{29}$ it has remained unclear if the reported apoptosis-inhibitory effects of crmA and VFLIP were due to death receptor signalling or due to the downstream mitochondrial pathway. Here, we present strong evidence for the latter, as SFV-induced caspase-8 and Bid processing was inhibited in Bak-/- and Bax/Bak DKO MEFs. As previously suggested, ${ }^{29,30}$ this downstream pathway may be necessary to further activate Bak (and Bax) by tBid, ensuring effective release of apoptogenic factors from mitochondria and the execution of both caspase-dependent and caspase-independent forms of cell death. For SFVinduced apoptosis, this indeed seems to be important as both Bid-/- and Bid/Bim DKO MEFs died in a significantly delayed manner.

Although it is generally accepted that both Bax and Bak are functionally redundant, it has been debated if their mode of activation is the same. In healthy cells/tissues, Bax is a cytoplasmic protein, ${ }^{31}$ whereas Bak is bound to mitochondria where it is inhibited by its interaction with voltage-dependent anion channel- $2^{32}$ or with the survival factors Bcl-2, Bcl- $x_{L}$ and Mcl-1. ${ }^{11,12}$ In response to apoptotic stimuli, Bax has to translocate to mitochondria before it can oligomerize and form pores. ${ }^{31}$ By contrast, activation of Bak appears to be much simpler, because it may just have to be released from $\mathrm{Bcl}-2$-like survival factors by the competitive binding of $\mathrm{BH}$ only proteins. ${ }^{11,12}$ This is probably what happens in response to SFV infection. The SFV system is therefore ideal to further elucidate the exact molecular mechanism of Bak activation. Other published examples of preferred Bak over Bax activation include apoptosis induction by the fungal toxin gliotoxin ${ }^{33}$ or the Bcl-2 family member Bcl- $x_{S} \cdot{ }^{34}$ Can we then exclude the contribution of Bax to SFV-induced apoptosis? Although slightly detectable in wt cells, the $\mathrm{N}$-terminal opening of Bax does not occur in Bak-/- cells, which continued to die at later time points. Moreover, perplexingly, Bax-/- MEFs are more sensitive to cytochrome $c$ release, $\Delta \Psi_{m}$ diminution, caspase- 3 activation, Bid cleavage and apoptosis than wt cells. These data are consistent with the findings by Lewis et al. ${ }^{35}$ that Bax-/- mice are more susceptible to SIN-induced neuronal disease and mortality than normal mice. The molecular basis of this rather death-protective action of Bax is unknown.

If the Bak-mediated mitochondrial pathway is so essential, why do Apaf-1-/-, caspase-9-/-, caspase-3/-7 DKO and even Bax/Bak DKO cells continue to die in response to SFV infection (Figures 1c, 2e, 3a and b)? It is known that mitochondrial membrane perforation also induces caspaseindependent death signalling that cannot be blocked by inhibiting the apoptosome or caspase-3/-7. This corroborates the finding that Bax/Bak DKO MEFs are more protected against SFV-induced apoptosis than Apaf-1-/- or caspase$9-1-$ cells (compare Figures $3 a$ and $2 e$ ). Indeed, we observed a maximally $50 \%$ reduction of cell death induced by both native and rSFV when the caspase inhibitor Q-VD$\mathrm{OPH}$ was included. In addition, we found that even Bax/Bak DKO cells still exhibited caspase- 3 processing and residual 
caspase- 3 activity beyond 24 h.p.i. (Figure $3 e$ and f). This result may explain why in some cells overexpression of $\mathrm{Bcl}-2$ cannot protect against SFV-induced apoptosis because it is inactivated by caspase-3-mediated cleavage of its $\mathrm{N}$ terminus (NT). ${ }^{22}$ How in this case caspase- 3 is activated remains to be determined.

The second important question is how SFV launches death signalling within its host. As shown here, initiation occurs during or after RNA replication. The involvement of the capsid serine protease in caspase processing/activation can be excluded because rSFV lacking its expression kills as efficiently as native viruses. Similarly, although Glasgow et al. $^{36}$ reported that a single mutation in E2 decreased the cytotoxicity and virulence of SFV in mice, we do not think that envelope proteins contribute greatly to the initiation of SFV-induced apoptosis. By contrast, the involvement of the non-structural cysteine protease nsP2 is more difficult to disentangle. Point mutations in nsP2 attenuate or suppress both the cytotoxicity and the shut-off of host protein synthesis, and therefore such mutations may be the basis for the development of new, less cytotoxic and non-cytotoxic SFV and SIN vectors. ${ }^{27,37}$ However, as nsP2 is also essential for RNA replication, it cannot be discriminated if its cytotoxic action is due to the lack of RNA production, the inhibition of protein synthesis or the processing/activation of initiator or effector caspases. Here we obtained evidence that inhibition of protein synthesis is not sufficient to trigger the apoptotic program. Firstly, apoptosis induced by the protein synthesis inhibitor cycloheximide is much slower and less efficient than SFV-induced apoptosis (Supplementary Material and Supplementary Figure 3A). Secondly, SFV-induced apoptosis does not lead to a major degradation of the labile survival factor Mcl-1 (Supplementary Figure 3B), a process recently shown to be crucial for apoptosis due to protein translation inhibition. ${ }^{38}$ Thirdly, double-stranded RNA (dsRNA)-activated protein kinase (PKR), a prominent mediator of protein synthesis shut-off in response to virus infection and a mediator of apoptosis in other cellular systems, ${ }^{26}$ does not seem to be involved in SFV-induced apoptosis, as PKR-/MEFs are as sensitive as wt cells (unpublished data). Despite this, dsRNA, which forms as an intermediate during SFV RNA replication, remains an attractive sensing component for host cell apoptosis. It will be interesting to know if the two recently identified dsRNA signalling pathways, the retinoic acid inducible gene-I and the melanoma differentiation-associated gene- 5 systems, play a crucial role in this respect. ${ }^{39}$

\section{Materials and Methods}

Antibodies and reagents. The following antibodies were used: rabbit polyclonal antibodies recognizing the conformation-specific N terminus of Bax and Bak (Bax NT, Bak NT) from Upstate Biotechnology; mouse monoclonal anti-mouse $\mathrm{Bcl}-2$ (clone 10C4) from Zytomed; mouse monoclonal anti-cytochrome $c$ antibodies detecting the native (clone $6 \mathrm{H} 2 . \mathrm{B} 4$, for immunofluorescence) or denatured (7H8.2C12, for western blotting) form from BD Pharmingen; rabbit polyclonal anti-caspase-3 antibodies, recognizing the inactive $32 \mathrm{kDa}$ proform (no. 9662) and the active $17 \mathrm{kDa}$ form (no. 9661) and mouse monoclonal anti-caspase-9 antibodies from Cell Signaling; mouse monoclonal anti-caspase-8 and anti-lysosomeassociated membrane protein-1 (anti-LAMP-1) antibodies from Alexis Biochemicals (San Diego, CA, USA); mouse monoclonal anti-actin (clone C4) antibody from MP Biomedicals; anti-FLAG (M2) antibodies from Sigma (USA); horseradish peroxidase-conjugated anti-rabbit or anti-mouse secondary antibodies from Jackson Immuno Research Laboratories (USA); Alexa Fluor 488-conjugated anti-mouse and Alexa Fluor 488 and Alexa Fluor 546-conjugated anti-rabbit secondary antibodies as well as mouse monoclonal anti-ATP synthase $(7 \mathrm{H} 10)$ antibody from Molecular Probes (USA). Rat monoclonal antibodies against Apaf-1 and against full-length Bid and tBid were a kind gift of DCS Huang, WEHI (Melbourne, VIC, Australia). Rabbit polyclonal antibody against the SFV capsid protein (SFV-C) was generously provided by J Pavlovic, University of Zürich, Switzerland.

The caspase inhibitor Q-VD-OPH was from MP Biomedicals, the fluorogenic caspase-3 substrate DEVD-AMC (acetyl-Asp(OMe)-Glu(OMe)-Val-Asp(OMe)-7amino-4-methylcoumarin) from Alexis Biochemicals and the DNA-dye PI from Sigma. His-GFP-annexin-V used for quantification of apoptosis was produced according to Egger et al. ${ }^{40}$ Recombinant tBid was a generous gift from J-C Martinou, University of Geneva, Switzerland.

Cells. The insect cell line Aedes albopictus was maintained at $28^{\circ} \mathrm{C}$ in $\mathrm{L} 15$ medium (Gibco) supplemented with 10\% fetal calf serum (FCS) and 4\% Difco Bacto phosphate tryptose broth. Baby hamster kidney cells (BHK-21), 3T9 and SV40immortalized MEFs and Vero cells were grown in high-glucose Dulbecco's modified Eagle's medium (DMEM) $(4.5 \mathrm{~g} / \mathrm{l}$ glucose) supplemented with $10 \% \mathrm{FCS}$. The various MEF cell lines were obtained from the following investigators. 3T9transformed wt, Bax-/-, Bak-/-, Bax/Bak DKO and SV40-transformed Bid-/from the late S Korsmeyer's lab, Dana Farber Cancer Institute, Boston, MA, USA; SV40-immortalized wt, caspase-3-1- and caspase-3/-7 DKO from R Flavell, Yale University, New Heaven, CT, USA; 3T9 wt and caspase-9-1- from YA Lazebnik, Cold Spring Harbor, NY, USA; and 3T9 wt and Apaf-1-/-, Bim-/-, Bad-/-, Bik-I-, Puma-I-, Noxa-I-, Bmf-I- and SV40-transformed Bim/Bad, Bid/Bim DKO from A Strasser (WEHI) and A Villunger, University of Innsbruck, Austria.

SFV production and titration. The SFV was produced by infecting the adherent mosquito cell line $A$. albopictus with an m.o.i. of 20 in L15 medium supplemented with $10 \% \mathrm{FCS}$ and $4 \%$ Difco Bacto phosphate tryptose broth. After culturing at $28^{\circ} \mathrm{C}$ for $24 \mathrm{~h}$, the supernatant was harvested and centrifuged at $3000 \times g$ for $10 \mathrm{~min}$ to remove cell debris. The supernatant was aliquotized and stored at $-80^{\circ} \mathrm{C}$. Virus yield was determined in culture supernatants collected from the various MEF cell lines infected with an m.o.i. of 10 by the so-called 'plaque assay.' Briefly, monolayers of Vero cells with $>90 \%$ confluency were infected with 10 -fold serial dilutions of virus in high-glucose DMEM supplemented with $2 \%$ FCS and $20 \mathrm{mM} \mathrm{HEPES}$ at $37^{\circ} \mathrm{C}$ for $90 \mathrm{~min}$. The inoculum was removed and replaced with an overlay of $0.4 \%$ noble agar (Difco, BD Diagnostics). Forty-eight hours later, the agar was removed, the monolayer was stained with $1 \%$ crystal violet and the plaques were counted.

Generation of recombinant viruses (replicon system). For safety reasons, the SFV expression system is based on two plasmid vectors (Figure 6a). (i) The expression vector, the so-called replicon (pSFV2subGFP), consists of the coding region of nsPs, which are responsible for viral RNA replication, and the two subgenomic $26 \mathrm{~S}$ promoters used for the expression of any desired foreign gene in conjunction with GFP (see above). (ii) The helper vector harbors the SFV structural genes. pSFV-Helper2 is the second generation of the SFV helper vector and it offers the additional safety feature of producing conditionally infectious particles. Mutations in the p62 precursor for the viral E2 and E3 spike proteins encoded by pHelper2 render the packaged SFV replicons cleavage-deficient and thus noninfectious. To infect cells, the $\mathrm{p} 62$ in the surface of these package replicons must be activated with $\alpha$-chymotrypsin. Furthermore, only the replicon RNA is packaged into rSFV particles because it contains a packaging signal required for encapsidation into the nucleocapsid, whereas the helper RNA does not (Figure 6a). This feature renders the generated virions suicidal, because, although they can replicate in their host cells, no progeny is generated, as the genetic material for production of the structural proteins is missing.

A $3 \mu \mathrm{g}$ portion of pSFV2subGFP and of pSFV-Helper2 were linearized with Nrul and Spel, purified and added to a 50- $\mu \mathrm{l}$ in vitro transcription mix (Promega) containing $1 \times$ transcription buffer, $1 \mathrm{mM} \mathrm{m7G}\left(5^{\prime}\right) \operatorname{ppp}\left(5^{\prime}\right) \mathrm{G}$ (cap analogue), $5 \mathrm{mM}$ dithiothreitol (DTT), $4 \mathrm{mM} \mathrm{rNTP} \mathrm{mix,} 100 \mathrm{U}$ RNase inhibitor and 50 U SP6 RNA polymerase. After incubation at $37^{\circ} \mathrm{C}$ for $90 \mathrm{~min}$, production of RNA was checked on $0.8 \%$ agarose gel. A $2 \mu \mathrm{g}$ portion of recombinant vector RNA and $2 \mu \mathrm{g}$ of helper RNA were electroporated into $5 \times 10^{6}$ BHK-21 cells by using Bio-Rad gene pulser-X (setting 1 pulse at $50 \mu \mathrm{F}, 700 \mathrm{~V}$ ). After culturing the electroporated cells in 
DMEM $+10 \%$ FCS for $48 \mathrm{~h}$, the viral supernatant was harvested and filtered through $0.22 \mu \mathrm{m}$ filter.

Viral infection. MEFs were grown to $80 \%$ confluency and infected with native SFV at an m.o.i. of 10 (in one case 200) in high-glucose DMEM supplemented with $0.5 \%$ FCS while shaking. After $1 \mathrm{~h}$ at $37^{\circ} \mathrm{C}$, viral infection was stopped with $10 \%$ FCS. At specified time points after infection, the supernatant was collected and virus yields were determined by plaque assay, as described above, or cells were harvested and used for FACS or western blot analysis.

For infections with recombinant pSFV2subGFP viruses, the viral stocks were first activated by incubating with $20 \mu \mathrm{g} / \mathrm{ml} \alpha$-chymotrypsin (Sigma) for 30 min at RT. The reaction was stopped with $10 \mu \mathrm{g} / \mathrm{ml}$ aprotinin for another $30 \mathrm{~min}$ at RT. After activation, the supernatant was layered on top of a $20 \%$ sucrose solution and ultracentrifuged at $160000 \times g$ for $90 \mathrm{~min}$ at $4^{\circ} \mathrm{C}$. The invisible virus pellet was resuspended in DMEM $+0.5 \%$ FCS and used to infect MEFs as described above for the native virus.

Immunofluorescence. MEFs were grown on glass coverslips overnight and then infected with SFV. At various time points post-infection, the cells were fixed in $4 \%$ paraformaldehyde and permeabilized in $0.1 \%$ Triton $X-100$, as described by Egger et al. ${ }^{40}$ The cells were then incubated with mouse monoclonal anticytochrome $c(10 \mu \mathrm{g} / \mathrm{ml}$; clone $6 \mathrm{H} 2 . \mathrm{B} 4)$ and polyclonal anti-caspase-3 (1: 100; no. 9661) antibodies for $90 \mathrm{~min}$ followed by Alexa Fluor 488-coupled goat anti-mouse and Alexa Fluor 546-coupled anti-rabbit secondary antibodies $(10 \mu \mathrm{g} / \mathrm{ml})$ for $90 \mathrm{~min}$. For colocalization of the SFV capsid protein with endosomal/lysosomal compartments, the cells were cotreated with polyclonal rabbit anti-SFV capsid antibody $(1: 200)$ and mouse monoclonal anti-LAMP-1 $(1: 1000)$ followed by incubation with rabbit and mouse Alexa Fluor secondary antibodies. Nuclei were stained with Hoechst 33334 ( $2 \mu \mathrm{g} / \mathrm{ml}$; Molecular Probes) for $5 \mathrm{~min}$. After treatment with the anti-fading agent Slow Fade (Molecular Probes) for $5 \mathrm{~min}$, the samples were directly viewed under a confocal Zeiss LSM 510 Meta microscope equipped with the software Zeiss LSM Examiner Version 4.2.0.121.

Protein extraction and western blot analysis. For total extracts, $2 \times 10^{6}$ MEFs were lysed in $\mathrm{H} 8$ buffer $(20 \mathrm{mM}$ Tris- $\mathrm{HCl} \mathrm{pH} 7.5,6 \mathrm{mM}$ $\beta$-mercaptoethanol, $2 \mathrm{mM}$ EDTA, $2 \mathrm{mM} \mathrm{EGTA}, 1 \% \mathrm{SDS})$ preheated to $95^{\circ} \mathrm{C}$. Preparation of cytosolic fractions for caspase assays was performed in homogenization buffer ( $2 \mathrm{mM} \mathrm{MgCl}_{2}, 25 \mathrm{mM}$ HEPES $\mathrm{KOH}, \mathrm{pH} 7.4,2 \mathrm{mM}$ EGTA, $100 \mu \mathrm{M}$ phenylmethylsulfonyl fluoride (PMSF), $10 \mu \mathrm{g} / \mathrm{ml}$ pepstatin, $10 \mu \mathrm{g} / \mathrm{ml}$ leupeptin, $5 \mu \mathrm{g} / \mathrm{ml}$ cytochalasin $\mathrm{B}, 10 \mu \mathrm{g} / \mathrm{ml}$ aprotinin, $10 \mathrm{mM}$ DTT) by five freeze-thawing cycles and centrifugation at $100000 \times g$ at $4{ }^{\circ} \mathrm{C}$ for $1 \mathrm{~h}$. Cytosolic and mitochondrial fractions for western blotting were obtained by lysing cells with a Biospec homogenizator in ice-cold MSH buffer $(210 \mathrm{mM}$ mannitol, $70 \mathrm{mM}$ sucrose, $20 \mathrm{mM}$ HEPES, $1 \mathrm{mM}$ EDTA, $100 \mu \mathrm{M}$ PMSF, $10 \mu \mathrm{g} / \mathrm{ml}$ pepstatin, $10 \mu \mathrm{g} / \mathrm{ml}$ leupeptin, $5 \mu \mathrm{g} / \mathrm{ml}$ cytochalasin $\mathrm{B}, 10 \mu \mathrm{g} / \mathrm{ml}$ aprotinin). The cell suspension was centrifuged at $400 \times g$ at $4{ }^{\circ} \mathrm{C}$ for 5 min to remove cell debris and nuclei, followed by centrifugation at $16000 \times g, 4^{\circ} \mathrm{C}$ for $1 \mathrm{~h}$ to obtain mitochondria. Ultracentrifugation of the post-mitochondrial sample at $100000 \times g$ for $1 \mathrm{~h}$ at $4{ }^{\circ} \mathrm{C}$ yielded the cytosol. Protein concentrations were determined with bichinonic acid assay. Equal amounts of protein from each fraction were separated by SDS-PAGE and then transferred onto polyvinylidene difluoride membranes. The membranes were incubated with the following antibodies: rabbit polyclonal antibody to inactive and active caspase-3 (1:1000), mouse monoclonal anti-cytochrome $c(1 \mu \mathrm{g} / \mathrm{ml}, 7 \mathrm{H} 8.2 \mathrm{C} 12)$, rabbit polyclonal anti-Bax-NT and anti-Bak-NT $(0.2 \mu \mathrm{g} / \mathrm{ml})$, mouse monoclonal antibody to caspase-8 $(2 \mu \mathrm{g} / \mathrm{ml})$, polyclonal rabbit anti-SFV capsid $(1: 2000)$, rat monoclonal anti-Bid $(1 \mu \mathrm{g} / \mathrm{ml})$, or mouse monoclonal anti-actin $(1: 40000$, clone $\mathrm{C} 4)$ and mouse monoclonal anti-ATP synthase $(1: 2000$, clone $7 \mathrm{H} 10)$ as loading controls. The secondary antibodies were horseradish peroxidase-conjugated anti-mouse, antirabbit $(0.16 \mu \mathrm{g} / \mathrm{ml})$ or anti-rat $(1.4 \mu \mathrm{g} / \mathrm{ml})$ antibodies.

Measurement of DEVDase (caspase-3/-7) activities. Caspase-3/-7 activities were assayed in the cytosol of infected cells by using the tetrapeptides Ac-Asp-Glu-Val-Asp conjugated to 7-amino-4-methylcoumarin $(60 \mu \mathrm{M}$, Alexis Biochemicals), as described by Egger et al. ${ }^{40}$

Gel filtration analysis of the apoptosome. Gel filtration was performed using an AEKTA explorer (Amersham Pharmacia) on a Superose $6(10 / 30)$ column equilibrated with homogenization buffer (see above). The column was calibrated with gel filtration standard proteins of the following molecular masses: blue dextran
(2000 kDa), thyroglobulin (669 kDa), ferritin (440 kDa), catalase (232 kDa), aldolase $(158 \mathrm{kDa})$ and bovine serum albumin $(66 \mathrm{kDa})$. A $400 \mu \mathrm{g}$ potion of cytosolic protein from mock- or SFV-infected ( $14 \mathrm{~h}$ ) MEFs was loaded in a $200 \mu$ linjection loop ( $2 \mathrm{mg} /$ $\mathrm{ml}$ protein), and the samples were run at $0.4 \mathrm{ml} / \mathrm{min}$. The eluate was monitored at $280 \mathrm{~nm}$. Fractions of $250 \mu \mathrm{l}$ were collected and pooled to $1 \mathrm{ml}$. The $1 \mathrm{ml}$ samples were subjected to a standard trichloroacetic acid precipitation and resuspended in sample buffer containing 3\% SDS. A $100 \mu \mathrm{l}$ portion of the sample was analyzed by anti-Apaf-1 immunoblotting.

Acknowledgements. We thank $A$ Strasser for the Apaf-1-/-, Bim-/-, Bad-/-, Bik-/-, Bim/Bad and Bim/Bid DKO MEFs; A Villunger for the Bmf-/-, Puma-/- and Noxa-/-MEFs; the late SJ Korsmeyer for the Bid-/-, Bax-/-, Bak-/- and Bax/Bak DKO MEFs; YA Lazebnik for the caspase-9-1- MEFs and the caspase-9 DN (C287S) construct; DCS Huang for the anti-Bid antibody and the FLAG-crmA construct; $H$ Walczak and $M$ Sprick for the leucine zipper-TRAIL, anti-TRAIL-R1 and TRAIL-R2-Fc; J Tschopp for the caspase-8 DN (C360S) construct; J Silke for the XIAP-FLAG construct; R Flavell for caspase-3-/- and caspase-3/-7 DKO cells; J Pavlovic for the anti-SFV-C antibody. MU Ehrengruber for the BHK-21 cells and the pSFV2subGFP construct and J-C Martinou for the recombinant tBid.

1. Strauss JH, Strauss EG. The alphaviruses: gene expression, replication, and evolution Microbiol Rev 1984; 58: 491-562.

2. Atkins GJ, Balluz IM, Glasgow GM, Mabruk MJ, Natale VA, Smyth JM et al. Analysis of the molecular basis of neuropathogenesis of RNA viruses in experimental animals: relevance for human disease? Neuropathol Appl Neurobiol 1994; 20: 91-102.

3. Levine B, Huang $Q$, Isaacs JT, Reed JC, Griffin DE, Hardwick JM. Conversion of lytic to persistent alphavirus infection by the bcl-2 cellular oncogene. Nature 1993; 361: 739-742.

4. Ubol S, Tucker PC, Griffin DE, Hardwick JM. Neurovirulent strains of Alphavirus induce apoptosis in bcl-2-expressing cells: role of a single amino acid change in the E2 protein. Proc Natl Acad Sci USA 1994; 91: 5202-5206.

5. Rheme C, Ehrengruber MU, Grandgirard D. Alphaviral cytotoxicity and its implication in vector development. Exp Physiol 2004; 90: 45-52.

6. Levine B, Goldman JE, Jiang HH, Griffin DE, Hardwick JM. Bcl-2 protects mice against fatal alphavirus encephalitis. Proc Natl Acad Sci USA 1996; 93: 4810-4815.

7. Tseng JC, Levin B, Hurtado A, Yee H, Perez de Castro I, Jimenez $M$ et al. Systemic tumor targeting and killing by Sindbis viral vectors. Nat Biotech 2004; 22: 70-76.

8. Xiong C, Levis R, Shen P, Schlesinger S, Rice CM, Huang HV. Sindbis virus: an efficient, broad host range vector for gene expression in animal cells. Science 1989; 243: 1188-1191.

9. Thorburn A. Death receptor-induced cell killing. Cell Signal 2004; 16: 139-144.

10. Simon NW, Adams JM. Life in balance: how BH3-only proteins induce apoptosis. Curr Opin Cell Biol 2005; 17: 617-625.

11. Willis SN, Chen L, Dewson G, Wie A, Naik E, Fletcher Jl et al. Proapoptotic Bak is sequestered by $\mathrm{Mcl}-1$ and $\mathrm{Bcl}-\mathrm{xL}$, but not $\mathrm{Bcl}-2$, until displaced by $\mathrm{BH} 3-$ only proteins Genes Dev 2005; 9: 1294-1305.

12. Ekert PG, Jabbour AM, Manoharan A, Heraud JE, Yu J, Pakusch $M$ et al. Cell death provoked by loss of interleukin-3 signaling is independent of Bad, Bim, and PI3 kinase, but depends in part on Puma. Blood 2006; 108: 1461-1468.

13. Kuwana T, Bouchier-Hayes L, Chipuk JE, Bonzon C, Sullivan BA, Green DR et al. BH3 domains of BH3-only proteins differentially regulate Bax-mediated mitochondria membrane permeabilization both directly and indirectly. Mol Cell 2005; 17: 525-535.

14. Green DR, Kroemer G. The pathophysiology of mitochondrial cell death. Science 2004; 305: 626-629.

15. Luo X, Budihardjo I, Zou H, Slaughter C, Wang X. Bid, a Bcl2 interacting protein, mediates cytochrome $c$ release from mitochondria in response to activation of cell surface death receptors. Cell 1998; 94: 481-490.

16. Boya P, Pauleau AL, Poncet D, Gonzalez-Polo RA, Zamzami N, Kroemer G. Viral proteins targeting mitochondria: controlling cell death. Biochim Biophys Acta 2004; 1659: 178-189.

17. Taylor JM, Barry M. Near death experiences: poxvirus regulation of apoptotic death. Virology 2006; 344: 139-150.

18. Bitzer M, Prinz F, Bauer M, Spiegel M, Neubert WJ, Gregor M et al. Sendai virus infection induces apoptosis through activation of caspase-8 (FLICE) and caspase-3 (CPP32). J Virol 1999; 73: 702-708.

19. Scallan MF, Allsoopp TE, Fazakerley JK. Bcl-2 acts early to restrict Semliki Forest virus replication and delays virus-induced programmed cell death. J Virol 1997; 71: 1583-1590.

20. Liang XH, Kleeman LK, Jiang HH, Gordon G, Goldman JE, Berry G et al. Protection against fatal Sindbis virus encephalitis by Beclin, a novel Bcl-2-interacting protein. J Virol 1998; 72 : 8586-8596.

21. Moriishi K, Koura M, Matsuura Y. Induction of Bad-mediated apoptosis by Sindbis virus infection: involvement of pro-survival members of the Bcl-2 family. Virology 2001; 292 258-271. 
22. Grandgirard D, Studer E, Monney L, Belser T, Fellay I, Borner C et al. Alphaviruses induce apoptosis in Bcl-2-overexpressing cells: evidence for a caspase-mediated, proteolytic inactivation of Bcl-2. EMBO J 1998; 17: 1268-1278.

23. Sarid E, Ben-Moshe T, Kazimirsky G, Weisberg S, Appel E, Kobiler D et al. vFLIP protects PC12 cells from apoptosis induced by Sindbis virus: implications for the role of TNF $\alpha$ Cell Death Differ 2001; 8: 1224-1231.

24. Nava V, Rosen A, Veliuona MA, Clem RJ, Levine B, Hardwick JM. Sindbis virus induces apoptosis through a caspase-dependent, crmA-sensitive pathway. J Virol 1998; 72: 452-459.

25. Jan JT, Griffin DE. Induction of apoptosis by Sindbis virus occurs at cell entry and does not require virus replication. J Virol 1999; 73: 10296-10302.

26. Zhang P, Samuel CE. Protein kinase PKR plays a stimulus- and virus-dependent role in apoptotic death and virus multiplication in human cells. J Virol 2007; 81: 8192-8200.

27. Fazakerley JK, Boyd A, Mikkola ML, Kääriäinen L. A single amino acid change in the nuclear localization sequence of the nsP2 protein affects the neurovirulence of Semlik Forest virus. J Virol 2002; 76: 392-396.

28. Lindsten T, Ross AJ, King A, Zong WX, Rathmell JC, Shiels HA et al. The combined functions of proapoptotic Bcl-2 family members bak and bax are essential for normal development of multiple tissues. Mol Cell 2000; 6: 1389-1399.

29. Cowling V, Downward J. Caspase-6 is the direct activator of caspase-8 in the cytochrome $c$-induced apoptosis pathway: absolute requirement for removal of caspase- 6 prodomain Cell Death Differ 2002; 9: 1046-1056.

30. Kuwana T, Smith JJ, Muzio M, Dixit VM, Newmeyer DD, Kornbluth S. Apoptosis induction by caspase- 8 is amplified through the mitochondrial release of cytochrome $c$. J Biol Chem 1998; 273: 16589-16594
31. Desagher S, Martinou JC. Mitochondria as the central control point of apoptosis. Trends Cell Biol 2000; 10: 369-377.

32. Cheng EH, Sheiko TV, Fisher JK, Craigen WJ, Korsmeyer SJ. VDAC2 inhibits BAK activation and mitochondrial apoptosis. Science 2003; 301: 513-517.

33. Pardo J, Urban C, Galvez EM, Müller U, Kwon-Chung J, Lobigs M et al. Bak is key in gliotoxin-induced apoptosis and a critical host factor of $A$. fumigatus virulence in mice. J Cell Biol 2006; 174: 509-519.

34. Lindenboim L, Kringel S, Braun T, Borner C, Stein R. Bak but not Bax is essential for Bcl- $\mathrm{x}_{\mathrm{S}}$-induced apoptosis. Cell Death Differ 2005; 12: 713-723.

35. Lewis J, Oyler GA, Ueno K, Fannjiang YR, Chau BM, Vornov J et al. Inhibition of virusinduced neuronal apoptosis by Bax. Nat Med 1999; 5: 832-835.

36. Glasgow GM, Killen HM, Liljeström P, Sheahan BJ, Atkins GJ. A single amino acid change in the E2 spike protein of a virulent strain of Semliki Forest virus attenuates pathogenicity. J Gen Virol 1994; 75: 663-668.

37. Garmashova N, Gorchakov R, Frolova E, Frolov I. Sindbis virus non-structural protein nsP2 is cytotoxic and inhibits cellular transcription. $J$ Virol 2006; 80: 5686-5696.

38. Adams KW, Cooper GM. Rapid turnover of MCL-1 couples translation to cell survival and apoptosis. J Biol Chem 2007; 282: 6192-6200.

39. Meylan E, Tschopp J, Karin M. Intracellular pattern recognition receptors in the host response. Nature 2006; 442: 39-44.

40. Egger L, Schneider J, Rhême C, Tapernoux M, Häcki J, Borner C. Serine proteases mediate apoptosis-like cell death and phagocytosis under caspase inhibiting conditions. Cell Death Differ 2003; 10: 1188-1203

\section{Supplementary Information accompanies the paper on Cell Death and Differentiation website (http://www.nature.com/cdd)}

